\title{
Molecular genetic testing of congenital adrenal hyperplasia due to 21-hydroxylase deficiency should include CAH-X chimeras
}

\author{
Qizong Lao $\mathbb{1}^{1} \cdot$ Deborah P. Merke $\mathbb{( i D}^{1,2}$
}

Received: 18 November 2020 / Revised: 3 February 2021 / Accepted: 11 March 2021 / Published online: 7 April 2021

This is a U.S. government work and not under copyright protection in the U.S.; foreign copyright protection may apply 2021

\section{To the Editor:}

We read with great interest the European Molecular Genetics Quality Network practice guidelines for molecular genetic testing of congenital adrenal hyperplasia $(\mathrm{CAH})$ due to CYP21A2 defects [1]. The authors address multiple important issues in the molecular genetic testing of $\mathrm{CAH}$ and provide valuable suggested standards based on extensive experience and practices from laboratories worldwide. While in general we agree with the workflow and methods described in the guidelines, we appeal to include evaluation for a contiguous gene deletion syndrome, termed CAH-X, within the scope of the testing. We believe this would be particularly beneficial for individuals carrying a $\mathrm{CAH}$ genotype of " $30 \mathrm{~kb}$ deletion".

As illustrated in Fig. 2 of the article by BaumgartnerParzer et al. [1], the terms " $30 \mathrm{~kb}$ deletion" or "large gene conversion" refer to a CAH genotype of chimeric genes caused by unequal crossover during meiosis due to the structural complexity of the CYP21A2 locus. These deletions account for $20-30 \%$ of all CAH alleles and are categorized into two subtypes determined by the location of the junction sites: $\mathrm{CAH}$ and $\mathrm{CAH}-\mathrm{X}$ chimeras [2]. $\mathrm{CAH}$ chimeras (CYP21A1P/CYP21A2) are caused by recombination between CYP21A1P and CYP21A2, and impair only CYP21A2; CAH-X chimeras (CYP21A1P-TNXA/TNXB) are caused by recombination between TNXA and TNXB, null the entire $C Y P 21 A 2$ and replace the $3^{\prime}$ of neighboring $T N X B$ with the pseudogene TNXA. This contiguous deletion is hence termed CAH-X, named for both CYP21A2 and TNXB

Deborah P. Merke

dmerke@nih.gov

1 Section on Congenital Disorders, National Institutes of Health Clinical Center, Bethesda, MD, USA

2 Eunice Kennedy Shriver National Institute of Child Health and Human Development, Bethesda, MD, USA defects. The latter is causative for hypermobility type Ehlers-Danlos syndrome (EDS) due to either deficiency or misfolding of its encoding tenascin- $\mathrm{X}$, a crucial component of the extracellular matrix [3-5].

Unlike the well documented CAH chimeras, CAH-X chimeras have often been missed and are typically omitted from the scope of CAH testing, even though this contiguous gene deletion was first reported in 1997 [3]. As a result, $\mathrm{CAH}-\mathrm{X}$ cases are reported as having a null $\mathrm{CAH}$ allele leading to lack of recognition and underestimation of $\mathrm{CAH}$ $\mathrm{X}$ prevalence. In fact, the prevalence of $\mathrm{CAH}-\mathrm{X}$ was recently estimated to be $15 \%$ in our large $\mathrm{CAH}$ cohort (278 subjects) in the U.S. followed at the National Institutes of Health Clinical Center (Bethesda, Maryland) and it was particularly prevalent $(30 \%)$ in the " $30 \mathrm{~kb}$ deletion" alleles [6]. Similarly, Gao et al. reported a $14 \% \mathrm{CAH}-\mathrm{X}$ prevalence in a large Chinese cohort (424 subjects) and a very high (59\%) prevalence in $\mathrm{CAH}$ alleles previously reported as "deletion" or "null" [7]. These reports indicate the necessity of revisiting the prevalence of CAH-X chimeras and addressing potential clinical implications of the $\mathrm{CAH}-\mathrm{X}$ syndrome, especially in subjects carrying an allele of " $30 \mathrm{~kb}$ deletion" or "large gene conversion".

CAH-X syndrome is composed of two elements: $\mathrm{CAH}$ and hypermobility type EDS; the former is autosomal recessive but the latter appears to be autosomal dominant. If carrying a $\mathrm{CAH}-\mathrm{X}$ allele, phenotypic EDS is expected regardless of the $\mathrm{CAH}$ status [2], although in general $\mathrm{CAH}$ patients have more severe EDS manifestations than their carrier counterparts $[4,5]$. The hypermobility EDS spectrum includes joint hypermobility, arthralgias, frequent joint dislocations, hernias and midline defects including cardiac structural abnormalities. Overall, about $25 \%$ of reported $\mathrm{CAH}-\mathrm{X}$ patients have cardiac abnormalities including congenital heart defects such as structural valve abnormalities, left ventricular diverticulum, and patent foramen ovale [8]. To date, the clinical diagnosis of EDS in CAH-X mostly relies on evaluation of joint hypermobility and subluxations, which are often restricted by factors such as age and time of 
onset. Genetic testing for this germline condition in newborn screening is advantageous in terms of offering very early diagnosis to young children before hypermobility evaluation is applicable, and to enable early screening for cardiac defects. In older individuals undergoing CYP21A2 genotyping, identification of $\mathrm{CAH}-\mathrm{X}$ would provide information regarding the cause of any ongoing connective tissue abnormalities and guidance regarding preventative measures. Treatment for hypermobility type EDS depends on the signs and symptoms present, and a screening echocardiogram should be considered.

To date, most $\mathrm{CAH}$ genetic test platforms determine the status of " $30 \mathrm{~kb}$ deletions". Adding a CAH-X test selectively to "30 kb deletion" positives can be a pinpoint addon. Sharing a ride with established DNA extraction and even PCR would optimize laboratory efficiency and costeffectiveness. For instance, laboratories that use a classic CYP779f/tena32F primer pair for PCR can use the same PCR product to conduct Sanger sequencing tests of $\mathrm{CAH}$ variants, 30-kb deletions and $\mathrm{CAH}-\mathrm{X}$ chimeras $[9,10]$. A high throughput CAH-X screening has been developed, which has shown excellent accuracy. It is amenable to either qPCR or digital PCR, thus it is fast and easy to operate [6]. If MPLA methodology is used, an up-to-date version now simultaneously checks " $30 \mathrm{~kb}$ deletion" and a CAH-X chimera of haploinsufficiency [1,7], therefore labs would only need to test the CAH-X chimeras of misfolding on " $30 \mathrm{~kb}$ deletion" positives to complete the $\mathrm{CAH}-\mathrm{X}$ test by either Sanger or qPCR/digital PCR methodologies.

In summary, CAH-X chimeras account for a large portion of " $30 \mathrm{~kb}$ deletion" $\mathrm{CAH}$ alleles and have historically been under-detected. Regardless of their $\mathrm{CAH}$ status, individuals who carry a CAH-X allele are expected to suffer from a spectrum of hypermobility EDS manifestations, including cardiac structural defects, joint hypermobility and instability, hernias and gastrointestinal disorders. Including $\mathrm{CAH}-\mathrm{X}$ determination in $\mathrm{CAH}$ molecular genetic testing platforms is convenient and cost-effective, and is particularly beneficial for individuals carrying a " $30 \mathrm{~kb}$ deletion" allele because many of them are in fact CAH-X. An early diagnosis of $\mathrm{CAH}-\mathrm{X}$ syndrome is valuable for preventative care and long-term medical management.

\section{Compliance with ethical standards}

Conflict of interest DPM received unrelated research funds from Diurnal Limited through the National Institutes of Health Cooperative
Research and Development Agreement. Both authors report no potential competing interests in this work.

Publisher's note Springer Nature remains neutral with regard to jurisdictional claims in published maps and institutional affiliations.

Open Access This article is licensed under a Creative Commons Attribution 4.0 International License, which permits use, sharing, adaptation, distribution and reproduction in any medium or format, as long as you give appropriate credit to the original author(s) and the source, provide a link to the Creative Commons license, and indicate if changes were made. The images or other third party material in this article are included in the article's Creative Commons license, unless indicated otherwise in a credit line to the material. If material is not included in the article's Creative Commons license and your intended use is not permitted by statutory regulation or exceeds the permitted use, you will need to obtain permission directly from the copyright holder. To view a copy of this license, visit http://creativecommons. org/licenses/by/4.0/.

\section{References}

1. Baumgartner-Parzer S, Witsch-Baumgartner M, Hoeppner W. EMQN best practice guidelines for molecular genetic testing and reporting of 21-hydroxylase deficiency. Eur J Hum Genet. 2020;28:1341-67.

2. Merke DP, Auchus RJ. Congenital adrenal hyperplasia due to 21hydroxylase deficiency. N Engl J Med. 2020;383:1248-61.

3. Burch GH, Gong Y, Liu W, Dettman RW, Curry CJ, Smith L, et al. Tenascin-X deficiency is associated with Ehlers-Danlos syndrome. Nat Genet. 1997;17:104-8.

4. Merke DP, Chen W, Morissette R, Xu Z, Van Ryzin C, Sachdev $\mathrm{V}$, et al. Tenascin-X haploinsufficiency associated with EhlersDanlos syndrome in patients with congenital adrenal hyperplasia. J Clin Endocrinol Metab. 2013;98:E379-87.

5. Morissette R, Chen W, Perritt AF, Dreiling JL, Arai AE, Sachdev $\mathrm{V}$, et al. Broadening the spectrum of Ehlers Danlos syndrome in patients with congenital adrenal hyperplasia. J Clin Endocrinol Metab. 2015;100:E1143-52.

6. Lao Q, Brookner B, Merke DP. High-throughput screening for CYP21A1P-TNXA/TNXB chimeric genes responsible for EhlersDanlos syndrome in patients with congenital adrenal hyperplasia. J Mol Diagn. 2019;21:924-31.

7. Gao Y, Lu L, Yu B, Mao J, Wang X, Nie M, et al. The prevalence of the chimeric TNXA/TNXB gene and clinical symptoms of Ehlers-Danlos syndrome with 21-hydroxylase deficiency. J Clin Endocrinol Metab. 2020;105:2288-99.

8. Miller WL, Merke DP. Tenascin-X, congenital adrenal hyperplasia, and the CAH-X syndrome. Horm Res Paediatr. 2018;89:352-61.

9. Lee HH, Lee YJ, Lin CY. PCR-based detection of the CYP21 deletion and TNXA/TNXB hybrid in the RCCX module. Genomics. 2004;83:944-50.

10. Xu Z, Chen W, Merke DP, McDonnell NB. Comprehensive mutation analysis of the CYP21A2 gene: an efficient multistep approach to the molecular diagnosis of congenital adrenal hyperplasia. J Mol Diagn. 2013;15:745-53. 